\title{
Study of prevalence of heart disease in antenatal mothers along with fetal and maternal outcome from a tertiary care hospital, Salem, Tamil Nadu, India
}

\section{Subha Sivagami Sengodan*, Shobhika Selvaraj}

Department of Obstetrics and Gynecology, Government Mohankumaramangalam Medical College Hospital, Salem, Tamil Nadu, India

Received: 17 September 2019

Accepted: 25 October 2019

\section{*Correspondence:}

Dr. Subha Sivagami Sengodan,

E-mail: drppsamysubha@gmail.com

Copyright: (c) the author(s), publisher and licensee Medip Academy. This is an open-access article distributed under the terms of the Creative Commons Attribution Non-Commercial License, which permits unrestricted non-commercial use, distribution, and reproduction in any medium, provided the original work is properly cited.

\section{ABSTRACT}

Background: Incidence of pregnancy in women with heart disease is increasing due to the increasing number of women with congenital heart disease. Although most cardiac conditions are well tolerated during pregnancy, there are some conditions that have adverse fetal and maternal outcome. Objective of this study is to study the prevalence of heart disease in antenatal mothers and fetal outcome with obstetric management.

Methods: This is a prospective observational study carried out in the Department of Obstetrics and Gynaecology at Government Mohan Kumaramangalam Medical College and Hospital during January 2018 to March 2019 for a period of fifteen months. Authors included 149 antenatal mothers with heart disease and analysed the data using percentage analysis through excel software.

Results: Incidence of heart disease in pregnancy was observed to be $1.2 \%$. Rheumatic heart disease being $73.8 \%$, congenital being $22.8 \%$ and complete heart block was 3.4\%. Among rheumatic heart disease mitral stenosis was the most common lesion. Atrial septal defect was the most common congenital heart disease. The mean gestational age of delivery was 37 to 38 weeks. $58 \%$ delivered by vaginal route. Most common neonatal complication was prematurity. Pregnancy and neonatal outcome were favorable.

Conclusions: Heart disease complicating pregnancy has increased due to late marriage, obesity, hypertension and diabetes. Early referral, regular follow-up and multi-disciplinary approach with tertiary care back-up will bring a favorable maternal and neonatal outcome in patients with heart disease.

Keywords: Antenatal mothers, Early referral, Heart disease, Multi-disciplinary approach, Prematurity, Rheumatic etiology

\section{INTRODUCTION}

Heart disease in pregnancy is one among the major medical problems complicating pregnancy. Heart disease is the third most common cause of maternal mortality, the other two being obstetric hemorrhage and pre-eclampsia. Incidence of pregnancy in women with heart disease is increasing in recent times and is a major cause of maternal morbidity and mortality. Pregnancy with heart disease is a high-risk pregnancy which needs vigilant monitoring by obstetricians and cardiologists. Rheumatic heart disease is the most common heart disease followed by congenital heart disease. Even though the incidence of rheumatic heart disease is decreasing in western countries, in developing countries like India rheumatic heart disease is the most common cause. In pregnancy 
normally blood volume increases, plasma volume increases, red blood cells increase, resistance changes to systemic circulation decreases, myocardial contractility increases and cardiac output increases. All these can be tolerated in normal pregnancy. But in already diseased heart it poses a major risk which requires close monitoring.

Incidence of heart disease complicating pregnancy is $1 \%$ to $4 \%$ in India. ${ }^{1}$ At present $0.2-0.4 \%$ of all pregnancies in western countries are complicated by cardiovascular disease. $^{2}$ In developing countries like India, cardiac diseases complicate $2 \%$ of pregnancies and contribute to about one- fifth of all maternal deaths. ${ }^{3}$ Rheumatic valvular heart disease is the most common cause in developing countries, comprising $56-89 \%$ of all cardiovascular diseases in pregnancy. ${ }^{4}$ Congenital heart block is uncommon, but can cause severe cardiovascular complications in pregnancy. Maternal heart disease is now the major cause of maternal deaths during pregnancy. ${ }^{5}$ Most of the cardiac disease are asymptomatic and can be diagnosed only at the time of delivery. Hence, any mild symptoms like chest pain, syncope, breathlessness, pedal odema and diastolic murmur should be considered seriously as it may be physiological in addition. Proper screening, regular antenatal check-ups, multi-disciplinary approach and follow-up is mandatory for a better maternal and fetal outcome.

\section{METHODS}

This is a prospective observational study carried out in the Department of Obstetrics and Gynaecology at Government Mohan Kumaramangalam Medical College and Hospital during January 2018 to March 2019 for a period of fifteen months. We included 149 antenatal mothers with heart disease and analysed the data using percentage analysis through excel software. Detailed history, clinical findings and examination were done in all patients.

\section{Inclusion criteria}

- $\quad$ The Patients with heart disease confirmed by echo.

\section{Exclusion criteria}

- $\quad$ Patients with gestational age less than 28 weeks

- Other associated maternal complications

- Women who were referred for termination of pregnancy.

\section{RESULTS}

A total of 149 pregnant women with cardiac diseases were included in the study. The incidence of cardiac disease in our hospital was observed to be $1.2 \%$. Of the 149 patient's majority were in the age group of 21-25 years $(36.9 \%)$ followed by the age group 26-30 years
$(30.9 \%)$. Patients in the age group between $18-20$ years were $23.5 \%$ (Table 1 ).

Table 1: Age wise distribution.

\begin{tabular}{|ll|}
\hline Maternal age (years) & Number $(\%)$ \\
\hline $18-20$ & $35(23.5 \%)$ \\
\hline $21-25$ & $55(36.9 \%)$ \\
\hline $26-30$ & $46(30.9 \%)$ \\
\hline $31-35$ & $8(5.4 \%)$ \\
\hline$>35$ & $5(3.3 \%)$ \\
\hline
\end{tabular}

Among the 149 pregnant women $66.4 \%$ were Primigravida, $28.9 \%$ were second Gravida and $4.7 \%$ were Gravida 3 or more (Table 2).

Table 2: Parity wise distribution.

\begin{tabular}{|ll|}
\hline Parity number & Number $(\%)$ \\
\hline Primigravida & $99(66.4 \%)$ \\
\hline Gravida 2 & $43(28.9 \%)$ \\
\hline Gravida 3 and more & $7(4.7 \%)$ \\
\hline
\end{tabular}

Of the 149 women, majority were term gestation $(55.7 \%)$ and $12.1 \%$ were pre-term gestation (Table 3 ).

Table 3: Gestational age wise distribution.

\begin{tabular}{|ll|}
\hline Gestational age (years) & Number $(\%)$ \\
\hline $28-32$ & $18(12.1 \%)$ \\
\hline $33-36$ & $44(29.5 \%)$ \\
\hline $37-40$ & $83(55.7 \%)$ \\
\hline$>40$ & $4(2.7 \%)$ \\
\hline
\end{tabular}

The prevalence of rheumatic heart disease was $73.8 \%$ followed congenital heart disease (22.8\%). The prevalence of congenital heart block was 3.8\% (Table 4).

Table 4: Prevalence.

\begin{tabular}{|ll|}
\hline Type of cardiac disease & Number $(\%)$ \\
\hline Rheumatic heart disease & $110(73.8 \%)$ \\
\hline Congenital heart disease & $34(22.8 \%)$ \\
\hline Congenital heart block & $5(3.4 \%)$ \\
\hline
\end{tabular}

Out of 5 patients who had congenital heart block 3 had intervention. Intervention for patients with congenital heart block in terms of permanent pacemaker were 2 $(66.7 \%)$ and temporary pacemaker was 1 (33.3\%) (Table $5)$.

Table 5: Intervention for congenital heart block.

\begin{tabular}{|ll|}
\hline Pacemaker type & Number $(\%)$ \\
\hline Permanent pacemaker & $2(66.7 \%)$ \\
\hline Temporary pacemaker & $1(33.3 \%)$ \\
\hline
\end{tabular}


The most common congenital lesion was atrial septal defect $(64.7 \%)$ followed by ventricular septal defect $(35.3 \%)$. Among the patients with rheumatic heart disease $50 \%$ had mitral stenosis, which is the most common lesion among rheumatic heart disease followed by $29.1 \%$ who had pulmonary stenosis. $10.9 \%$ had mitral regurgitation followed by $7.3 \%$ who had both mitral stenosis and mitral regurgitation. Aortic stenosis was found in $2.7 \%$ of the antenatal mothers (Table 6).

Table 6: Type of lesion.

\begin{tabular}{|lcl|}
\hline $\begin{array}{l}\text { Type of lesion } \\
\text { Congenital heart disease }\end{array}$ & Number & Percentage \\
\hline \multicolumn{2}{|l|}{} \\
\hline ASD & 22 & $64.7 \%$ \\
\hline VSD & 12 & $35.3 \%$ \\
\hline Rheumatic heart disease & \\
\hline MS & 55 & $50 \%$ \\
\hline PS & 32 & $29.1 \%$ \\
\hline MR & 12 & $10.9 \%$ \\
\hline AS & 3 & $2.7 \%$ \\
\hline MS + MR & 8 & $7.3 \%$ \\
\hline
\end{tabular}

Most of the patients with heart disease belong to NYHA class $1(47.7 \%)$ followed by NYHA class $2(44.9 \%) .2 \%$ of the patients belong to NYHA class 4. Patients belonging NYHA class 3 and 4 had adverse fetal and maternal outcome (Table 7).

Table 7: NYHA class.

\begin{tabular}{|ll|}
\hline Class & Number $(\%)$ \\
\hline Class 1 & $71(47.7 \%)$ \\
\hline Class 2 & $67(44.9 \%)$ \\
\hline Class 3 & $8(5.4 \%)$ \\
\hline Class 4 & $3(2 \%)$ \\
\hline
\end{tabular}

Majority of the patients had vaginal delivery (58\%) and LSCS was done for $42 \%$ (Table 8).

Table 8: Mode of delivery.

\begin{tabular}{|ll|}
\hline Delivery & Number $(\%)$ \\
\hline Vaginal & $86(58 \%)$ \\
\hline LSCS & $63(42 \%)$ \\
\hline
\end{tabular}

Table 9: Indication for LSCS.

\begin{tabular}{|ll|}
\hline Indication for LSCS & Number (\%) \\
\hline Fetal distress with non-reassuring CTG & $22(34.9 \%)$ \\
\hline CPD & $10(15.8 \%)$ \\
\hline Failed Induction & $8(12.7 \%)$ \\
\hline Previous LSCS & $8(12.7 \%)$ \\
\hline Malpresentation & $4(6.4 \%)$ \\
\hline Hypertension & $4(6.4 \%)$ \\
\hline Abruptio placenta & $3(4.7 \%)$ \\
\hline Gestational diabetes & $2(3.2 \%)$ \\
\hline Cord prolapse & $2(3.2 \%)$ \\
\hline
\end{tabular}

The most common indication for LSCS in our hospital is fetal distress with non-reassuring CTG followed by CPD. Failed induction and previous LSCS are also major indications for LSCS accounting for about 25\% (Table 9).

Table 10: Maternal complication.

\begin{tabular}{|ll|}
\hline Complication & Number $(\%)$ \\
\hline Anemia & $86(64.2 \%)$ \\
\hline Preeclampsia & $28(20.9 \%)$ \\
\hline Pulmonary odema & $12(9 \%)$ \\
\hline Abruptio placenta & $4(3 \%)$ \\
\hline Congestive cardiac failure & $2(1.5 \%)$ \\
\hline Pulmonary arterial hypertension & $2(1.5 \%)$ \\
\hline Maternal mortality & $0(0 \%)$ \\
\hline
\end{tabular}

Of the 149 deliveries, patients who went in for complication were 134. Of maternal complications, $64.2 \%$ patients had anemia followed by $20.9 \%$ who had preeclampsia. $9 \%$ of the patients were complicated with pulmonary odema. $1.5 \%$ of the patients went in for congestive cardiac failure. $3 \%$ of patients had abruption. Maternal mortality was nil (Table 10).

Table 11: Neonatal outcome.

\begin{tabular}{|ll|}
\hline Outcome & Number $(\%)$ \\
\hline Prematurity & $55(56.1 \%)$ \\
\hline IUGR & $28(28.6 \%)$ \\
\hline Birth asphyxia & $4(4 \%)$ \\
\hline MSAF & $8(8.2 \%)$ \\
\hline Perinatal mortality & $3(3.1 \%)$ \\
\hline
\end{tabular}

Of 98 NICU admissions prematurity was observed in $56.1 \%$ and intra uterine growth restriction (IUGR) in $28.6 \%$. $4 \%$ of babies had birth asphyxia and $8.2 \%$ of babies had MSAF. There were 3 perinatal deaths of which 1 still born at 36 weeks and 2 neonatal deaths, out of which 1 was due to severe IUGR died after 7 days of the birth, the other was due to severe birth asphyxia, died after 1 day of birth (Table 11).

\section{DISCUSSION}

In developed countries, congenital heart disease is now more common in the pregnant population than acquired heart disease. But in developing countries like India acquired heart disease (rheumatic etiology) is the most common cause. With the use of antibiotics against streptococcus the incidence of rheumatic heart disease is decreasing. The rates of maternal death related to structural congenital heart disease have declined progressively, suggesting that the level of awareness may have increased and, thus, may have led to improved management of pregnant women with various congenital heart defects. ${ }^{6,7}$ Rheumatic endocarditis causes most of the mitral stenotic lesion. In pregnancy this causes heart failure due to fluid overload. Aortic stenosis in women 
less than 30 years is usually a congenital lesion and is due to congenital bicuspid valve. Moderate aortic stenosis is well tolerated but severe aortic stenosis is life threatening due to decreased preload. Pulmonary valve is least affected by rheumatic fever than others. Severe pulmonary stenosis is associated with right heart failure and atrial arrhythmias. Mitral regurgitation is found even in normal patients. But if there is improper adjustment of mitral valve leaflets during systole abnormal degrees of mitral regurgitation may develop. This is followed by left ventricular dilation and eccentric hypertrophy. Atrial septal defect is the most common congenital heart disease. Risk of endocarditis in atrial septal defect is negligible. Secondum type of atrial septal defect is most common. Pregnancy is well tolerated unless pulmonary hypertension develops.

Ventricular septal defect lesions close spontaneously during childhood. Most of them are paramembraneous. Physiological derangements are related to lesion size. If the lesion size is less than 1.25 square $\mathrm{cm}$ then no complications occur. Adults with large lesion size and un-repaired lesion develop left ventricular failure and pulmonary hypertension. Pregnancy is usually well tolerated. But if pulmonary arterial pressure reaches systemic levels there is bidirectional flow (Eisenmenger's syndrome) and pregnancy in this state should essentially be terminated. Ischemic heart disease is rapidly increasing in the pregnant population and is now the commonest cause of cardiac death in pregnancy in the UK. $^{8}$ This is likely due to increased maternal age, smoking, the adoption of a sedentary lifestyle and poor diet leading to greater rates of obesity, diabetes and hypertension. Rheumatic heart disease remains prevalent in many developing countries. ${ }^{9}$ In pregnancy there is a physiological alteration in the cardiovascular system. Women with an underlying heart disease may worsen during pregnancy. Hence, the maternal outcome depends upon the ability to adapt the cardiovascular changes. The incidence of cardiac disease in pregnancy in our study was $1.2 \%$. This study shows the most common cause was rheumatic etiology $(73.8 \%)$ followed by congenital heart disease $(22.8 \%)$. The most common valvular lesion was mitral stenosis $(50 \%)$ followed by pulmonary stenosis $(29.1 \%)$. Isolated pulmonary stenosis is usually well tolerated during pregnancy. ${ }^{10}$ Rheumatic heart disease complicates about $0.3 \%$ to $3.5 \%$ of women in the childbearing period with a global figure of $1 \%{ }^{11}$ It accounts for about $30 \%$ of cardiac disease during pregnancy in developed countries and $90 \%$ of heart disease in developing countries. ${ }^{12,13}$ Of the 149 women in the study group, $66.4 \%$ were Primigravida with a mean gestational age of delivery between 37 to 40 weeks. Majority of the patients $(92.6 \%)$ belong to NYHA class 1 and class 2. NYHA Class 3 and Class 4 was observed in $7.4 \%$ of the patients and had a poor outcome. These observations were comparable with the study done by Indira et al. ${ }^{14}$ Of the 149 deliveries $68 \%$ delivered vaginally and $42 \%$ had cesarean section. The most common indication for LSCS is fetal distress with non- reassuring CTG. In our study maternal complication was observed in 134 patients $(89.9 \%)$ with cardiac disease. Of which 86 had anemia, 28 had preeclampsia followed by pulmonary odema in 12 patients. Abruption was observed in 4 patients. 2 of them had congestive cardiac failure. In our hospital due to vigilant monitoring and ICU care the maternal mortality was nil. In this study authors had 98 NICU admission due to prematurity, IUGR, birth asphyxia and MSAF. Authors had 3 perinatal mortality, 1 due to severe IUGR and 2 dues to respiratory distress syndrome. Identification of heart disease before pregnancy or early in the first trimester may improve the pregnancy outcome.

\section{CONCLUSION}

Heart disease in pregnancy is a major cause of maternal mortality, preterm birth and perinatal mortality. Favourable outcome depends on age, socioeconomic status, type of heart disease, frequent antenatal check-ups and co-morbid conditions.

Heart disease complicating pregnancy has increased in recent times due to late marriage and other risk factors like lifestyle modification, obesity, hypertension, diabetes and rheumatic etiology. Early diagnosis, regular followup, strict vigilance and multi-disciplinary approach with tertiary care management will bring a favourable maternal and neonatal outcome in patients with heart disease.

\section{Funding: No funding sources}

Conflict of interest: None declared

Ethical approval: The study was approved by the Institutional Ethics Committee

\section{REFERENCES}

1. Bansode BR. Pregnancy and heart disease. Assoc Physicians Ind. 2010;773-6.

2. Vera RZ, Carina BL, Claudio B, Renata C, Rafael F, Jean MF. ESC guidelines on the management of cardiovascular diseases during pregnancy. Eu Heart J. 2011;3147-97.

3. Stangl V, Schad J, Gossing G, Borges A, Baumann G, Stangl K. Maternal heart disease and pregnancy outcome: A single-centre experience. Eur J Heart Fail. 2008;10:855-60.

4. Siu SC, Sermer M, Colman JM, Alvarez AN, Mercier LA, Morton BC, et al. Prospective multicenter study of pregnancy outcomes in women with heart disease. Circulation. 2001;104:515-21.

5. CEMACH. CEMACH saving mothers' Lives: reviewing maternal deaths to make motherhood safer-2003-2005: the seventh report on confidential enquiries into maternal deaths in the United Kingdom. Centre for Maternal and Child Enquiries, London; 2008.

6. Siu SC, Sermer M, Colman JM Cardiac disease in pregnancy (CARPREG) investigators. Prospective 
multicenter study of pregnancy outcome in women with heart disease. Circulation. 2001;104:515-21.

7. Siu SC, Colman JM, Sorensen S. Adverse neonatal and cardiac outcomes are more common in pregnant women with cardiac disease. Circulation. 2002;105:2179-84.

8. Steer PJ. Pregnancy and contraception. In: adult congenital heart disease: a practical guide. Gatzoulis M, Swan L, Therrien J, Pantley G (Eds). Blackwell Publishing, London, UK; 2005;16-36.

9. Carapetis JR. The current evidence for the burden of group A streptococcal diseases. WHO/FCH/CAH/05·07, WHO, Geneva; 2004;1-57.

10. Hameed AB, Goodwin TM, Elkayam U. Effect of pulmonary stenosis on pregnancy outcomes - a casecontrol study. Am Heart J. 2007;154(5):852-4.

11. Mohamed R, Awni G. Maternal and fetal outcome in women with rheumatic heart disease. Arch Gynecol Obstet. 2016;273-8.
12. Siu SC, Sermer M, Colman JM, Alvarez AN, Mercier LA, Morton BC, et al. Prospective multicenter study of pregnancy outcomes in women with heart disease. Circulation. 2001;104(5):515-21.

13. Carapetis JR, Steer AC, Mulholland EK, Weber M. The global burden of group A streptococcal diseases. Lancet Infect Dis. 2005;685-94.

14. Indira I, Sunitha K, Jyothi. Study of pregnancy outcome in maternal heart disease. IOSR J Dental Med Sci. 2015;14(7):6-10.

Cite this article as: Sengodan SS, Selvaraj S. Study of prevalence of heart disease in antenatal mothers along with fetal and maternal outcome from a tertiary care hospital, Salem, Tamil Nadu, India. Int J Reprod Contracept Obstet Gynecol 2019;8:5027-31. 